\title{
An Attempt of Geopolymer Synthesis from Construction Waste
}

\author{
Vinay Kumar Jha* and Anupama Tuladhar \\ Central Department of Chemistry, Tribhuvan University, Kirtipur, Kathmandu, Nepal \\ Tel. No.:+977-1-4332034 (O), E-mail:vinayj2@yahoo.com
}

\begin{abstract}
Recently, the demolition of old houses and the construction of new buildings in Kathmandu valley are in the peak which in turn generates a huge amount of construction waste. This construction waste is rich source of alumino-silicate and thus used as raw material for the synthesis of geopolymer in this study. Geopolymers have been synthesized from construction waste using $\mathrm{NaOH}$ and $\mathrm{Na}_{2} \mathrm{SiO}_{3}$ as activators. Some parameters like alkali concentration, ratio of $\mathrm{Na}_{2} \mathrm{SiO}_{3}$ to construction waste and curing time have been varied in order to improve the quality of geopolymeric product. The results obtained revealed the maximum compressive strength of $7.3 \mathrm{MPa}$ at the ratio of sodium silicate to construction waste of 0.5 $(w / w)$ on 15 days curing time at $40^{\circ} \mathrm{C}$ temperature.
\end{abstract}

Keywords: Geopolymer, Construction waste, Alkali activator, Compressive strength.

\section{Introduction}

According to the United Nation Statistics Division (UNSD) "wastes are materials that are not prime products (i.e. product produced in the market ) for which the generator has no further use in terms of his/her own purposes of production, transformation or consumption \& of which he/she wants to dispose". Waste may be generated during the extraction and processing of raw materials into intermediate and final products, the consumption of final products and other human activities ${ }^{1}$.

In recent years, demolition of old buildings and construction of new ones in most of the major cities are in peak. But due to rapid urbanization and increasing population the empty land spaces are decreasing while land prices are increasing. Several million tons of concrete waste are produced every year due to frequent building demolition and have resulted in drastic reduction in available landfill space due to industrialization and urbanization.

The major composition of the construction waste is sand and cement which are the major sources of $\mathrm{Al}_{2} \mathrm{O}_{3}$ and $\mathrm{SiO}_{2}$. The prominent application of the alumino-silicate rich materials are the synthesis of light weight aggregates, decontamination of feed contaminated by fungi and mycotoxins, synthesis of zeolites and geopolymer etc.

The term "geopolymer" was coined by Davidovits in 1972 to the tri-dimensional alumino-silicate that are formed at the low temperature and short time by naturally occurring alumino-silicate ${ }^{2}$. "Geopolymer" describes a family of mineral binders that have polymeric Si-O-Al framework structure similar to that found in zeolites because they have approximately same Al: Si ratio.

Geopolymer cement is synthesized from raw material containing alumino-silicate at low temperature which leads to significant reduce in energy consumption \& $\mathrm{CO}_{2}$ emission. It is reported by Davidovits that about 3/5 less energy is required \& 80- $90 \%$ less $\mathrm{CO}_{2}$ is generated for the production of geopolymer cement than that of ordinary Portland cement $(\mathrm{OPC})^{3}$. Thus geopolymer cement reduces global warming and saves energy. Furthermore, geopolymer cement possesses high temperature resistance up to $1200^{\circ} \mathrm{C}$ without properties degradation. This merit of geopolymer can be applied in automotive and aerospace

\section{*Corresponding Author}


industries. At present, some geopolymeric products have been used in aircraft to eliminate cabin fire and other aircraft accidents ${ }^{4}$.

The primary work on geopolymerization was done on kaolinite and metakaolinite by Davidovits. The mixture of granulated blast furnace slag, kaolinite and metakaolinite showed the highest compressive strength of $79 \mathrm{MPa}$ at 28 days \& $60^{\circ} \mathrm{C}$ curing time \& temperature ${ }^{5,6}$. Geopolymer synthesized from metakaolinite at $65^{\circ} \mathrm{C}$ curing temperature for 35 days curing time had the compressive strength of 35 MPa7. The adhesive strength of maetakaolinite based geopolymer coating on stainless and mild steel substrate with the composition of $\mathrm{Si}$ : $\mathrm{Al}=2.5$ were found to have the strength $>3.5 \mathrm{MPa}$ when cured at $70^{\circ} \mathrm{C}^{8}$. The coal combustion fly ashes based geopolymers had gained the compressive strength about 60 $\mathrm{MPa}$ when treated with $12 \mathrm{M} \mathrm{NaOH}$ and cured at $80^{\circ} \mathrm{C}$ for 48 hours ${ }^{9}$. High strength geopolymers with compressive strength over $100 \mathrm{MPa}$ were obtained from coal fly ash, blast furnace slag with potassium silicate solution and water, in which the fly ash was the major the component ${ }^{10}$. The geopolymers with compressive strength in the range of 12.5-56 MPa were synthesized from fly ash (FA) and rice husk ash (RHA) in which sodium silicate to $\mathrm{NaOH}$ mass ratio was 4 and curing temperature and time were $60^{\circ} \mathrm{C}$ for 48 hours respectively ${ }^{11}$. The geopolymers from mechanochemically treated clinoptilolite using $\mathrm{NaOH}$ and sodium silicate solutions showed increasing compressive strength up to around $25 \mathrm{MPa}$ with increasing curing time ${ }^{12}$.

Construction waste is the growing problem in many countries \& the present work is the preliminary investigation on the possibility of utilizing construction waste as raw materials in the production of geopolymer cement in order to find out the amicable solution for such problem.

\section{Experimental Methods}

\section{Sample Preparation}

The construction waste (CW) was selected from demolition area near New Road, Kathmandu and did not include brick and gravel. At first, the pieces of concrete was ground in iron mortar using pestle with constant sieving until the grain size was reduced to $<100 \mu \mathrm{m}$. The powder was then chemically modified with $\mathrm{NaOH}$ (Qualigens Chemical, India) of various concentrations at room temperature. The $\mathrm{NaOH}$ treated sample was then filtered until the filtrate became neutral to litmus paper and dried in oven at $80^{\circ} \mathrm{C}$ for 4hrs (N6c, Philips, Harris, England).

\section{Preparation of $\mathrm{CW}$ base geopolymer}

To synthesize geopolymer from concrete waste, several parameters like alkali concentration, amount of sodium silicate \& curing time were varied. The $2.0 \mathrm{~g} \mathrm{NaOH}$ treated $\mathrm{CW}$ was blended manually for 2 minutes with required $\mathrm{NaOH}$ concentration using mortar and pestle. The mixture was then transferred to plastic mould measuring $10 \mathrm{~mm}$ diameter by $10 \mathrm{~mm}$ high which was sealed to prevent water loss. The air bubbles were removed with the help of ultrasonicator (Bransonic, USA). After 4 hours curing at $40^{\circ} \mathrm{C}$ in oven, the samples were demoulded. The top face of the sample was made parallel to the bottom and area of the sample was measured. The compressive strength of the sample was measured using Maruto Testing Machine (s56A, Japan). From this step the most appropriate concentration of $\mathrm{NaOH}$ solution to be used with varying amount of sodium silicate in next step was determined.

The $2.0 \mathrm{~g} \mathrm{CW}$ previously treated with $5 \mathrm{~N} \mathrm{NaOH}$ solution was blended manually with $5 \mathrm{~N} \mathrm{NaOH}$ solution and varying amount of sodium silicate (sd fine chemicals, India) using mortar and pestle. As mentioned above the mixture was thoroughly mixed for 2 minutes and transferred to plastic mould. Then the moulds were cured for 5 days and compressive strength was measured. From this step, the most appropriate mass ratio of sodium silicate to concrete waste to be used for curing time variation in next step was determined.

The mass ratio of sodium silicate to $\mathrm{CW}$ of $0.5 / 2.0$ was mixed with $5 \mathrm{M} \mathrm{NaOH}$ solution manually. The mixture was moulded and cured for 5-15 days in oven at $40^{\circ} \mathrm{C}$. The compressive strength of the sample with varying curing time was measured. 


\section{Results and Discussion}

\section{Compressive Strength with $\mathrm{NaOH}$ Concentration Variation}

Figure 1 represents the compressive strength of geopolymeric products with the variation of $\mathrm{NaOH}$ concentration. The compressive strength initially increased and then decreased showing the maximum strength of $3.2 \mathrm{MPa}$ at $5 \mathrm{~N} \mathrm{NaOH}$.
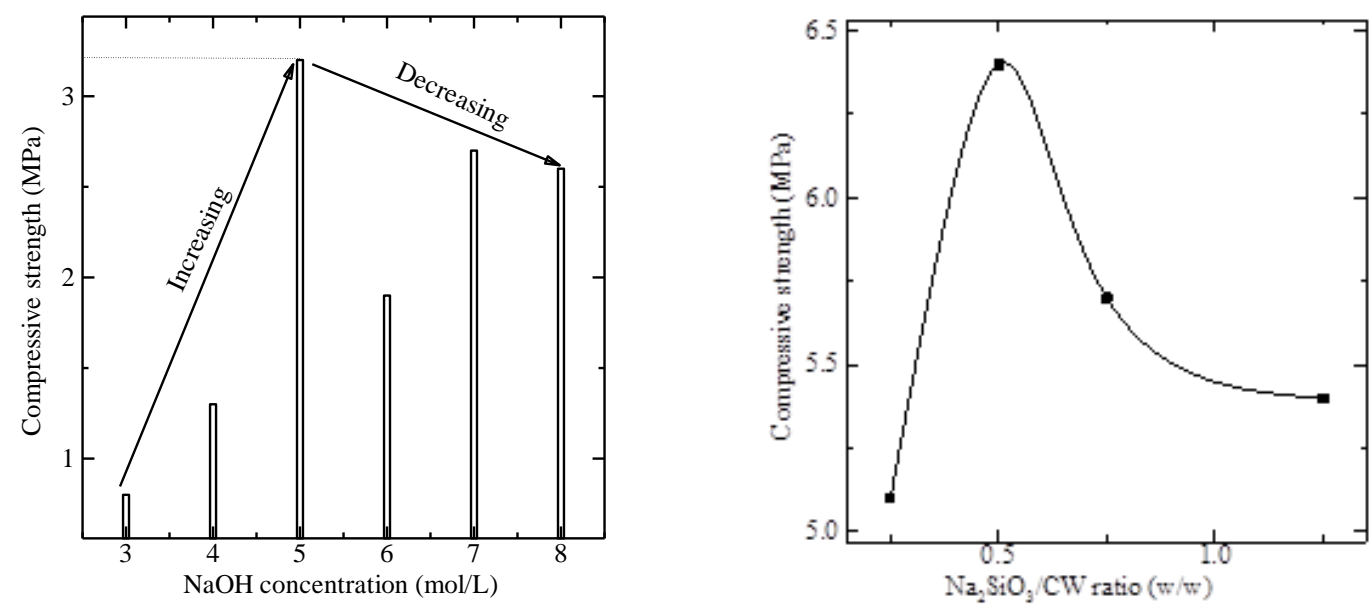

Figure 1(left): Plot of compressive strength as a function of $\mathrm{NaOH}$ concentration. Figure 2(right): Plot of compressive strength as a function of mass ratio of $\mathrm{Na} 2 \mathrm{SiO} 3 \mathrm{toCW}$.

The above results can be interpreted as: the dissolution of alumino-silicate take place under alkaline solution and the higher amount of hydroxyl ion facilitate the dissolution of different silicate and aluminate species promoting polymerization ${ }^{13-14}$. But under high alkaline condition the connectivity of silicon anion may be reduced which causes alumina-silicate gel to precipitate at early stage resulting in poor polymerization i.e. $\mathrm{NaOH}$ molecule is incorporated between two geopolymer precursors which break the silicon anion connectivity thus preventing polymerisation ${ }^{15}$.

Further, the excess $\mathrm{NaOH}$ forms $\mathrm{Na}_{2} \mathrm{CO}_{3}$ by atmospheric carbon ${ }^{16}$. Due to these reasons, the excess concentration of $\mathrm{NaOH}$ causes the decrease in compressive strength. Having small size, $\mathrm{Na}^{+}$can form strong pair with small silicate oligomers and thus stabilize silicate monomer and dimmer; enhancing mineral dissolution ${ }^{17}$.

\section{Compressive Strength with Sodium silicate to $\mathrm{CW}$ ratio}

Fig. 2 represents the compressive strength of geopolymeric product achieved at 5 days of curing at $40^{\circ} \mathrm{C}$ with various silicate concentrations. The compressive strength of geopolymer was first found to increase and decreased with maximum compressive strength of 6.4 MPa.

It can be well observed from Fig. 2 that after the addition of $\mathrm{Na}_{2} \mathrm{SiO}_{3}$ the compressive strength nearly doubled. This is because at higher concentration of silicates, the stronger ion pair formation is expected which results in formation of longer chain silicate oligomer as well as Al-O-Si complexes ${ }^{18}$. Thus added silica acts as a binder shown in the reaction below. But the increased silica decreases the rate of geopolymerization ${ }^{19}$ and also in high silica system; solidification of the paste prior to reaction completion may occur ${ }^{20}$. This may be the probable reason why increase in amount of silicate causes decreases in compressive strength. 
Further, it is believed that the amount of unreacted materials in the specimen with higher silica content act as the defect site and has the negative effect on strength5.

$$
\begin{gathered}
\mathrm{n}\left(\mathrm{Si}_{2} \mathrm{O}_{5} \mathrm{Al}_{2} \mathrm{O}_{2}\right)+\underset{\mathrm{OH}}{2 \mathrm{nSiO}}{ }_{2}+4 \mathrm{nH}_{2} \mathrm{O} \stackrel{\mathrm{NaOH} / \mathrm{KOH}}{\longrightarrow} \mathrm{n}(\mathrm{OH})_{3}-\mathrm{Si}-\mathrm{O}-\mathrm{Al}-\mathrm{O}-\mathrm{Si}-(\mathrm{OH})_{3} \\
\mathrm{n}(\mathrm{OH})_{3}-\mathrm{Si}-\mathrm{O}-\underset{\mathrm{I}}{\mathrm{Al}}-\mathrm{O}-\mathrm{Si}-(\mathrm{OH})_{3} \stackrel{\mathrm{I}}{\stackrel{\mathrm{NaOH} / \mathrm{KOH}}{\longrightarrow}}\left(\mathrm{Na}^{+} / \mathrm{K}^{+}\right)-(\mathrm{Si}-\mathrm{O}-\mathrm{Al}-\mathrm{O}-\mathrm{Si}-\mathrm{O})+4 \mathrm{nH}_{2} \mathrm{O} \\
\mathrm{OH} \\
\quad \text { (Geopolymer backbone) }
\end{gathered}
$$

In formula (1) $\left(\mathrm{SiO}_{5} \mathrm{Al}_{2} \mathrm{O}_{2}\right)$ is an emphasized form to stand out the IV fold co-ordination of $\mathrm{Al}$ instead of conventional alumino-silicate oxides form of $\left(2 \mathrm{SiO}_{2} \cdot \mathrm{Al}_{2} \mathrm{O}_{3}\right) \cdot \mathrm{SiO}_{2}$ in formula (1) is a monomer or polymer form which comes from silicate added later. Formula (2) shows the final backbone of the geopolymer and charge balance in the matrix.

\section{Compressive Strength with Curing Time Variation}

Fig. 3 represents the compressive strength values achieved with the variation of curing time ranging from 5 days to 15 days at $40^{\circ} \mathrm{C}$. The compressive strength increases with increase in the curing time with the maximum compressive strength of $7.3 \mathrm{MPa}$. The strength continues to rise further as shown in the graph.

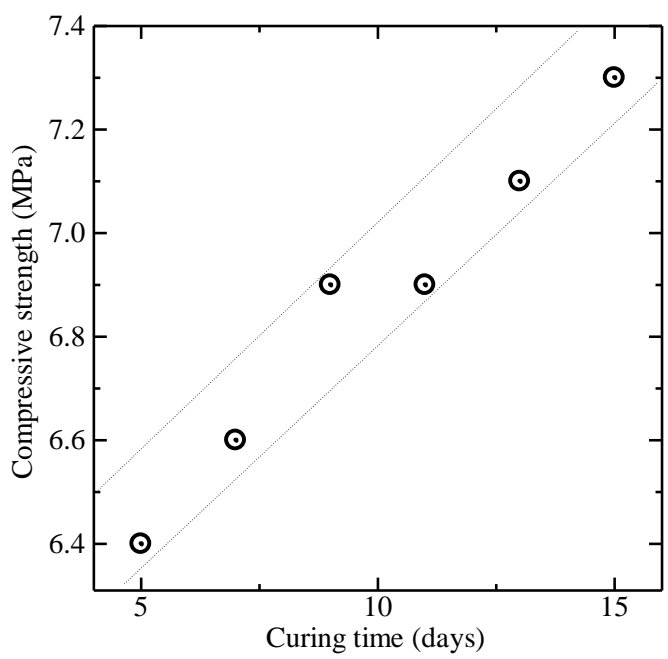

Figure 3: Plot of compressive strength as a function of curing time.

Unlike cement, which has fixed life span about 50 years and after which compressive strength decreases, the strength of geopolymer tends to rise. Egyptian pyramid can be taken as the example. This is because once the stable 3D structure of geopolymer is formed it can stay intact for centuries until and unless crack develop due to several reasons like earthquake and also the resistivity against fire, chemical and high temperature $\left(1200^{\circ} \mathrm{C}\right)$ add the quality of geopolymer but these parameters deteriorates the cement rapidly.

The curing for longer period of time at low temperature is preferable for the synthesis of geopolymer as at low temperature condensation of geopolymer precursors and evaporation of the water molecules takes place simultaneously preventing the formation of voids and cracks inside the material thus increasing the compressive strength. 


\section{Conclusion}

The geopolymer was synthesized by using various concentration of alkali activator i.e. $\mathrm{NaOH}$ and $\mathrm{Na}_{2} \mathrm{SiO}_{3}$. The parameter like $\mathrm{pH}$, amount of silicate and curing time were studied at $40^{\circ} \mathrm{C}$ curing temperature. The following conclusions were drawn from the experimental results of the study:

The compressive strength was found initially increasing and then decreased with increasing $\mathrm{NaOH}$ concentration. The maximum compressive strength of 3.2 MPa was obtained with concrete waste treated with $5 \mathrm{M} \mathrm{NaOH}$ solution. With the variation of sodium silicate the compressive strength increased initially and decreased with higher concentration of sodium silicate showing $6.8 \mathrm{MPa}$ with $1 / 2(\mathrm{~g} / \mathrm{g})$ mass ratio of $\mathrm{Na}_{2} \mathrm{SiO}_{3}$ to concrete waste. The increase in compressive strength with increase in curing time suggests that curing for longer time period at ambient temperature is preferable for the synthesis of geopolymer of higher compressive strength.

\section{Acknowledgements}

Authors are thankful to Nepal Academy of Science and Technology (NAST), Khumaltar, Lalitpur for the financial support and to Dr. Chiranjibi Regmi (Faculty Chief of Technology Department of NAST) for providing the necessary instrumental help for the measurement of compressive strength of solid samples.

\section{References}

1. Glossary of Environment Statistics, Studies in Methods, United nations, N.Y., Series F, No. 67, 1997.

2. J. Davidovits and J. Orlinski, (Eds.), Proc. 1st Int'l Conf. on Geopolymer '88, Compiegne, France, 1988, 1, 19.

3. J. Davidovits, Proc. 1st Int'l Conf. on Alkaline Cements and Concretes, SRIBM, Kiev, Ukraine, 1994, 1, 131.

4. Comrie Preliminary examination of the potential of geopolymers for use in mine tailings management, Ontario, Canada, 1988.

5. J. Davidovits, US Patent-4, 1984, 472, 199.

6. T.W. Cheng and J. P. Chiu, Miner. Eng., 2003, 16, 205.

7. H. Wang, H. Li and F. Yan, Colloids Surf. A: Physicochem. Eng. Asp., 2005, 268, 1.

8. T. Jadambaa, M. Amgalan, R. William, L. Melissa, W. Lestyn and R. ArieVan, Appl. Clay Sci., 2009, 46, 265.

9. E.A. lvarez-Ayuso, X. Querol, F. Plana, A. Alastuey, N. Moreno, M. Izquierdo O. Font, T. Moreno, S. Diez, E.V.'azquez and B. Barra, J. Hazard. Mater., 2008, 154, 175.

10. H.W. Nugteren, V.C.L. Butselaar-Orthlieb and M. Izquierdo, Global NEST J., 2009, 11, 155.

11. S. Detphan and P. Chindaprasirt, J. Miner. Metall. Mater., 2009, 16, 720.

12. V.K. Jha and S. Hayashi, Science and Technical Reports of Faculty of Engineering and Resource Science, Akita University, 2009, 30, 35.

13. J. Davidovits and J. Orlinski (Eds.), Proc. 1st Int'l Conf. on Geopolymer '88, Compiegne, France, 1988, 1, 25.

14. C.K. Yip, G.C. Lukey and J.S.J. Van Deventer, Cem. Concr. Res., 2005, 35, 1688.

15. P.S. Singh, T. Bastow and M. Trigg, J. Mater. Sci., 2005, 40, 3951.

16.V.F.F. Barbosa, K.J.D. MacKenzie and C. Thaumaturgo, Proc. 2nd Int'l Conf. on Geopolymer '99, Saint Qunentin, France, 1999, 65.

17. K. Komnitsas, and D. Zaharaki, Miner. Eng., 2007, 20, 1261.

18. A.V. McCormick, A.T. Bell and C.J. Radke, J. Phy. Chem., 1989, 93, 1741.

19. J.L. Provis and J. S. G. Van Deventer, Chem. Eng. Sci., 2007, 62, 2309.

20. J.L. Provis and J. S. G. Van Deventer, J. Mater. Sci., 2007, 42, 2974. 